\title{
Clinical Toxicology
}

\section{Treatment of methyl bromide poisoning with haemodialysis}

\author{
M.R. Moosa, J. Jansen and C.L. Edelstein \\ Renal and Intensive Care Units, Tygerberg Hospital and Department of Internal Medicine, University of \\ Stellenbosch, Cape Town, South Africa
}

\begin{abstract}
Summary: Acute accidental methyl bromide poisoning was treated with haemodialysis. The treatment was successful in removing bromide from the blood but the patient persists with severe neuropsychiatric sequelae. To the best of our knowledge haemodialysis has not been used previously for the treatment of organic bromide poisoning.
\end{abstract}

\section{Introduction}

The success of much of the world's food production is dependent on the application of methyl bromide $(\mathrm{MBr})$ which is used for the disinfection of soil, food storage facilities and greenhouses. ${ }^{1} \mathrm{MBr}$ is an odourless, colourless gas at normal temperature and atmospheric pressure and is extremely toxic to man with fatalities and serious morbidity being reported even with the use of 'appropriate' protective measures. ${ }^{2}$ Most reported cases of acute poisoning have been accidental with occupational exposure posing the greatest risk. ${ }^{3}$ Treatment of $\mathrm{MBr}$ poisoning has largely been supportive. Earlier this century inorganic salts of bromide were used in the treatment of 'nervous' disorders and, since the drugs were readily available without prescription, cases of intoxication were commonly seen. ${ }^{4}$ Haemodialysis is considered the ideal treatment for acute inorganic bromide intoxication. ${ }^{5}$ Since $\mathrm{MBr}$ may be hydrolysed to bromide and methanol, both of which are eminently dialysable, we decided to attempt haemodialysis in a patient who had suffered acute $\mathrm{MBr}$ poisoning and who failed to respond to conservative treatment. ${ }^{6}$

\section{Case report}

A previously healthy 56 year old man presented 12 hours after accidental exposure to $\mathrm{MBr}$ while

Correspondence: M.R. Moosa, M.B., Ch.B., F.C.P. (S.A.), Ward A7, Renal Unit, Tygerberg Hospital, Private bag, Parow, Cape Town, Republic of South Africa 7505.

Accepted: 29 March 1994 cleaning a rice silo. The patient was obtunded and suffering severe myoclonic seizures that failed to settle on a combination of intravenous diazepam, clonazepam and phenytoin. He was haemodynamically stable but his lungs sounded moist. There was no personal history of seizures.

His initial serum calcium was $2.1 \mathrm{mmol} / 1$ (corrected), magnesium $0.86 \mathrm{mmol} / \mathrm{l}$, sodium 143 $\mathrm{mmol} / \mathrm{l}$, potassium $3.5 \mathrm{mmol} / \mathrm{l}$, chloride $114 \mathrm{mmol} /$ 1 , urea $3.6 \mathrm{mmol} / 1$, creatinine $62 \mu \mathrm{mol} / 1$ and total carbon dioxide $16.2 \mathrm{mmol} / \mathrm{l}$. Arterial blood gas analysis on admission revealed a partial pressure of oxygen on room air of $10.6 \mathrm{kPa}$, a partial pressure of carbon dioxide of $3.8 \mathrm{kPa}$, and a pH of 7.38. The patient's blood cell counts and urinalysis were normal. The liver enzymes were normal initially but progressively deteriorated, and peaked 16 days after hospital admission at which time the aspartate transaminase activity was $98 \mathrm{U} / 1$ (normal up to $40 \mathrm{U} / \mathrm{l}$ ), the alanine transaminase activity was $167 \mathrm{U} / 1$ (normal up to $53 \mathrm{U} / \mathrm{l}$ ), the lactate dehydrogenase activity $429 \mathrm{U} / 1$ (normal $100-350 \mathrm{U} / \mathrm{l}$ ), the gamma glutamyl transferase activity was $187 \mathrm{U} / 1$ (normal up to $50 \mathrm{U} / \mathrm{l}$, and the alkaline phosphatase activity was $177 \mathrm{U} / 1$ (normal 30-85 $\mathrm{U} / \mathrm{l})$. The liver enzymes normalized after 2 weeks. No ethanol was detected in the patients' blood.

After failing to respond to the initial treatment for the myoclonic convulsions, the patient was transferred to the intensive care unit (ICU), where he underwent endotracheal intubation and intermittent positive pressure ventilation (IPPV). His seizures were controlled on thiopentone and pancuronium. An electro-encephalogram performed before the patient was paralysed showed changes compatible with metabolic disturbances but no 
focal abnormalities were demonstrated. Arterial blood gases normalized on IPPV. Bromide levels in the blood were estimated. The initial serum level of bromide was $130 \mathrm{mg} / \mathrm{l}$. Overnight a forced diuresis was produced with normal saline administered intravenously together with frusemide in an attempt to enhance the elimination of the $\mathrm{MBr}$. The serum bromide level was repeated 25 hours after the first estimation following a brisk diuresis. Since there was no significant change in the levels and the patient's clinical condition had shown no improvement, the patient underwent a 5 hour haemodialysis treatment. No bromide was detected in the blood tested subsequent to dialysis.

The patient was ventilated for 20 days. Attempts at earlier weaning were frustrated by recurring severe myotonic convulsions. Nosocomial infections of the urinary tract and airways required aggressive antibiotic treatment. When the patient was finally weaned from the ventilator, he was receiving phenytoin, clonazepam and sodium valproate, which controlled his myotonic convulsions. The patient was transferred to the ward where his convulsions continued for a further 2 weeks before settling.

At this time, the extent of neurological damage became apparent. He was noted to have severe psychomotor retardation associated with blunting of his affect. His movements were slow, tremulous and stiff suggesting extrapyramidal disease. He also had urinary incontinence. The patient was discharged $\mathbf{4 8}$ days after admission for rehabilitation. One year later the patient is still very severely handicapped by neuropsychiatric disease. $\mathrm{He}$ is confined to a wheelchair, is incontinent and entirely dependent on others for assistance with activities of daily living.

\section{Method}

The patient was dialysed on a Fresenius A2008C dialysis machine. A Fresenius F6 low-flux polysulphone dialyser with a surface area of $1.3 \mathrm{~m}^{2}$ was used. The dialysate flow rate was $500 \mathrm{ml} /$ minute. A central venous catheter was used to deliver blood to the machine with return via a peripheral vein at a rate of $200 \mathrm{ml} /$ minute. Heparin was administered in the blood line to the dialyser. Dialysis was terminated after 5 hours. Blood specimens for the estimation of bromide were drawn on admission to the ICU and then 25 hours following the commencement of forced diuresis. Further samples were collected at the initiation of dialysis therapy and hourly for the duration of dialysis treatment. These blood samples were paired with samples of dialysate collected simultaneously. At approximately 12 and 24 hours after the dialysis treatment further samples were taken. The blood and dialysate samples were analysed for bromide using gas chromatography with mass spectrometric detection. $^{7}$

\section{Results}

With forced diuresis and diuretics the serum bromide level only decreased from $130 \mathrm{mg} / \mathrm{l}$ to $120 \mathrm{mg} / 125$ hours later. In sharp contrast the bromide levels declined exponentially when haemodialysis was initiated (Figure 1). No bromide was detected in the blood tested 12 hours and 24 hours after dialysis. All the dialysate samples contained bromide but for technical reasons this could not be quantified.

\section{Discussion}

The hallmark of severe $\mathrm{MBr}$ intoxication is the acute resistant myoclonic convulsions, which require muscle relaxation and IPPV for control. ${ }^{8}$ $\mathrm{MBr}$ causes very severe and permanent mental and neurological damage, and the prevention of $\mathrm{MBr}$ poisoning is therefore of paramount importance. Its use should be limited to experienced persons employing reliable and tested safety equipment. Accidents will, however, continue to occur even with the best precautions and, therefore, methods of treatment that are effective need to be sought. ?

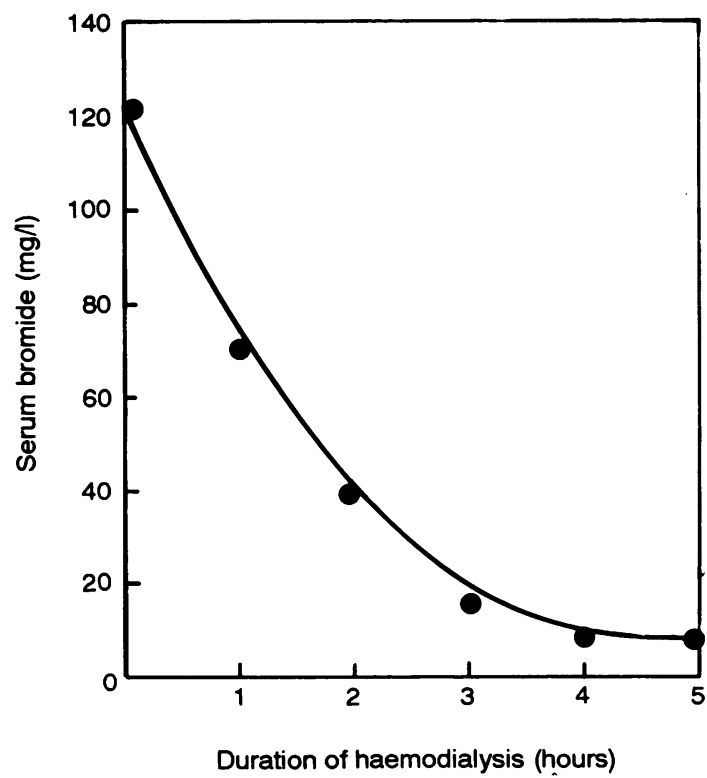

Figure 1 Response of serum bromide levels to haemodialysis. 
The fate of $\mathrm{MBr}$ in the body is unknown but it has been postulated that the toxin is hydrolysed to methanol and inorganic bromide both of which are readily removed by dialysis. ${ }^{6}$ Bromide is a relatively small ion that is handled by the body in a similar fashion to chloride. ${ }^{5}$

Like chloride, it is distributed predominantly in the extracellular fluid, and excretion is very slow and solely by the renal tubules. The small molecular size of the bromide ion, as well as its predominantly extracellular distribution, the high plasma content, theoretically makes it an ideal dialysable toxin'. 5 The successful application of haemodialysis for the treatment of inorganic bromide intoxication prompted us to use this therapy in this case of $\mathrm{MBr}$ poisoning. The rapid lowering of the blood bromide levels in our patient, following the 5 hour haemodialysis and its permanent clearance from the blood appears to indicate that we were successful in this regard. The other metabolite of $\mathrm{MBr}$ is methanol, which has also been implicated in the toxicity of methyl bromide. The failure of our patient, however, to improve clinically would seem to suggest that delay in the treatment resulted in irreparable damage to very sensitive neural tissue. In addition, the bromide blood levels do not reflect the cerebrospinal fluid changes in the levels. The delay in the reequilibration of bromide across the blood-brain barrier is well known and accounts in some cases for the delay in the improvement in the clinical picture after dialysis for inorganic bromide intoxication. $^{5}$

The pathogenesis of the neurological involvement remains uncertain. There is some evidence that $\mathrm{MBr}$ has a high affinity for sulphydryl groups. ${ }^{9}$ Studies in rats have implicated metabolic and neurotransmitter changes in the pathogenesis of $\mathrm{MBr}$ neurotoxicity. Glutathione-S-transferase inhibition and glutathione (GSH) depletion were detected in various parts of the brain. ${ }^{10}$ The use of GSH may therefore be an useful adjunct in the treatment of severe $\mathrm{MBr}$ intoxication. Dimercaptopropanol has also been used successfully in the treatment of $\mathrm{MBr}$ poisoning. ${ }^{11}$

In conclusion, the early use of haemodialysis should be considered in the treatment of acute $\mathrm{MBr}$ poisoning to remove the bulk of the toxin, perhaps together with substances that interfere with the action of $\mathrm{MBr}$ at a cellular level.

\section{Acknowledgements}

We are grateful to Ms B.K. Williamson of the South African Forensics Chemistry Laboratory for the chemical analyses, and Drs M. Cassidy and D. Parkin for reviewing the manuscript.

\section{References}

1. Van Oetingen, W.F. The Halogenated Hydrocarbons of Industrial and Toxicological Importance. Elsevier, Amsterdam, 1964.

2. vd Oever, R. Actual hazard of methyl bromide fumigation in soil disinfection. Br J Indust Med 1982, 39: 140-144.

3. Wheather, R.H. Hazard of methylbromide fumigant exposure. JAMA 1976, 236: 1510.

4. Adamson, J.S., Flanigan, W.J. \& Ackerman, G.L. Treatment of bromide intoxication with ethacrynic acid and mannitol diuresis. Ann Intern Med 1966, 65: 749-752.

5. Schreiner, G.E. The role of haemodialysis (artificial kidney) in acute poisoning. Arch Intern Med 1958, 102: 896-913.

6. Miller, D.P. \& Haggard, H.W. Intracellular penetration of bromide as a feature in the toxicity of alkyl bromides. $J$ Indust Hyg Toxicol 1943, 25: 423-433.

7. Corina, D.L., Ballard, K.E., Grice, D., Eade, O.E. \& Lucas, $\mathrm{K}$. Bromide measurements in serum and urine by an improved gas-chromatographic method. J Chromatog (Biomed Applic) 1979, 162: 382-387.

8. Behrens, R.H. \& Dukes, D.C.D. Fatal methyl bromide poisoning. Br J Indust Med 1986, 43: 561-562.

9. Lewis, S.E. Inhibition of SH proteins by methyl bromide. Nature 1948, 161: 692-693.

10. Davenport, C.J., Ali, S.F., Miller, F.J., Lipe, G.W., Morgan, K.T. \& Bonnefoi, M.S. Effect of methyl bromide on regional brain glutathione, glutathione-S-transferases, monoamines, and amino acids in F344 rats. Toxicol Appl Pharmacol 1992, 112: $120-127$.

11. Rathaus, E.M. \& Semely, P.J. Methyl bromide poisoning. $\mathrm{Br}$ $J$ Indust Med 1961, 18: 53-57. 